\title{
MODIFICACIONES ANATÓMICAS Y QUÍMICAS EN EL LEÑO DE EJEMPLARES del arbolado de la ciudAd de LA Plata (Buenos Aires) CAUSADAS POR LAETIPORUS SUlPHUREUS (BASIDIOMYCOTA, Polyporales)
}

\author{
MÓNICA MURACEE ${ }^{1,5}$, MARÍA L. LUNA ${ }^{2,3}$, MARIA G. G.CIUFFANI ${ }^{1,5}$ y ANALÍA PERELLÓ ${ }^{4,5}$
}

\begin{abstract}
Summary: Anatomical and chemical modifications in the wood of specimens of trees of La Plata city (Buenos Aires) caused by Laetiporus sulphureus (Basidiomycota, Polyporales). L. sulphureus is an important pathogen causing brown rot in urban trees worldwide. In La Plata city, this fungus was found in specimens of white poplar, green ash, eucalyptus and chinaberry. The objective of this study was to analyze the structural and chemical alterations caused by L. sulphureus in white poplar, green ash, eucalyptus and chinaberry in order to contribute to the diagnosis of the risk that implies their deterioration for inhabitants, their goods and tree diversity in the city. Anatomical studies were performed using light and scanning electron microscopes. Chemical analyses were carried out on samples of green ash and chinaberry, according to TAPPI standards. In all instances the damage was located in the heartwood, showing typical characteristics of advanced stages of brown rot decay. For each species specific alterations at the anatomical and chemical levels were registered, compatible with their structural differences. This is the first regional contribution on the type and degree of deterioration recorded in species naturally affected by $L$. sulphureus, useful for understanding the risks involved in the urban context.
\end{abstract}

Key words: Laetiporus sulphureus, hardwoods, brown-rot, chemical-anatomical alterations.

Resumen: A nivel mundial, Laetiporus sulphureus es un importante patógeno causante de pudriciones castañas en el arbolado urbano. En la ciudad de La Plata, dicho hongo fue hallado en ejemplares de álamo blanco, fresno americano, eucalipto y paraíso gigante. El objetivo del trabajo fue analizar las alteraciones estructurales y químicas ocasionadas por $L$. sulphureus en el leño de álamo blanco, fresno americano, eucalipto y paraíso gigante con el propósito de dimensionar el riesgo que implica su deterioro para los habitantes, sus bienes y la diversidad arbórea de la ciudad. Los estudios anatómicos fueron realizados con microscopios óptico y electrónico de barrido. Los análisis químicos se llevaron a cabo en muestras de fresno y paraíso, según normas TAPPI. En todos los ejemplares el daño se localizó en el duramen, registrándose caracteres típicos de estadios avanzados de pudrición castaña. En cada especie se registraron alteraciones particulares a nivel anatómico y químico, compatibles con las diferencias estructurales entre ellas. Esta es la primera contribución regional sobre el tipo y grado de deterioro registrados en especies infectadas naturalmente por $L$. sulphureus, de utilidad para la comprensión de los riesgos que ello implica en el contexto urbano.

Palabras clave: Laetiporus sulphureus, leño de latifoliadas, pudrición castaña, alteraciones químicoanatómicas.

${ }^{1}$ Cátedra Protección Forestal mmurace@gmail.com

2 Cátedra Morfología Vegetal, Facultad de Ciencias Naturales y Museo, UNLP. Edificio Anexo Museo, Unidades de Investigación. Boulevard 120 y 61 (1900), La Plata.

${ }^{3}$ Comisión de Investigaciones Científicas de la Provincia de Buenos Aires (CIC-BA).

${ }^{4}$ Cátedra Fitopatología-CIDEFI-CONICET.

${ }^{5}$ Facultad de Ciencias Agrarias y Forestales, UNLP, calle 60 y 119 (1900) La Plata, Buenos Aires, Argentina. 


\section{INTRODUCCIÓN}

Los árboles constituyen un elemento esencial dentro del diseño urbano dados los múltiples beneficios ambientales, paisajísticos y socioculturales que aportan a las ciudades (Urcelay et al., 2012). En este contexto, una de las particularidades que destacan a la ciudad de La Plata desde su época fundacional - en 1882 - es su arbolado público, pese a la notable regresión en diversidad y números de ejemplares identificada principalmente desde fines del siglo XX. La presión demográfica y la infraestructura que ello demanda afectan negativamente la composición del arbolado de los espacios públicos (Municipalidad de La Plata, 1983; Delucchi et al., 1993), al igual que el deficiente estado sanitario, en particular cuando es debido a la actividad de los hongos xilófagos. Estos organismos, responsables de las pudriciones de la madera, disminuyen la resistencia al quiebre de las ramas y/o troncos de los ejemplares, lo cual pone en riesgo la composición del patrimonio forestal, la vida de los habitantes y sus bienes (Terho \& Hallaksela, 2005; Urcelay et al., 2012).

Laetiporus sulphureus (Bull.) Murrill., es reconocido como un importante patógeno de especies arbóreas, responsable de provocar pudrición castaña del duramen en madera de latifoliadas y coníferas de ejemplares vivos en pie (Ota et al., 2009).

En las pudriciones castañas los carbohidratos de la pared celular son despolimerizados y la lignina es parcialmente oxidada (Green \& Highley, 1997; Gamauf et al., 2007; Riley et al., 2014). La despolimerización de la celulosa y las hemicelulosas afecta negativamente las propiedades de resistencia de la madera desde las primeras etapas del proceso de degradación y, a causa de ello, el alto riesgo que significa la presencia de este tipo de deterioro en los árboles (Schwarze et al., 2000b).

Debido a la escasa información a nivel mundial y particularmente en Argentina sobre los daños que provoca $L$. sulphureus en ejemplares vivos, el objetivo del trabajo fue estudiar las alteraciones anatómicas y químicas ocasionadas por este xilófago en el leño de álamo blanco, fresno americano, paraíso y eucalipto, latifoliadas de alta frecuencia en el arbolado público de la ciudad de La Plata.

El conocimiento del deterioro causado por este patógeno en árboles del contexto urbano contribuye a dimensionar el riesgo de su presencia para los habitantes, sus bienes y la diversidad arbórea, aportando información valiosa para la toma de decisiones en el marco de un plan de manejo compatible con este tipo de ambiente.

\section{Materiales y Métodos}

\section{Identificación fúngica}

La identificación de L. sulphureus fue realizada a partir de los rasgos macro y microscópicos de los basidiomas presentes en el leño expuesto de ejemplares en pie vivos, de acuerdo con las especificaciones de Robledo \& Urcelay (2009), como así también a partir del estudio del micelio asociado a dicho material. Pequeños trozos de madera con evidencias de pudrición y micelio fueron cultivados en agar malta al $2 \%$ suplementado con antibiótico $\left(5 \mathrm{ml} / 200 \mathrm{~cm}^{3}\right.$ medio, de composición: $1 \mathrm{~g}$ estreptomicina; $0,5 \mathrm{~g}$ cloranfenicol $/ 200 \mathrm{ml} \mathrm{de}$ agua destilada estéril) y benomil $\left(48 \mathrm{ml} / 200 \mathrm{~cm}^{3} \mathrm{de}\right.$ medio, de composición: $0,3 \mathrm{~g} / \mathrm{l}$ de agua destilada estéril) e incubados a $25^{\circ} \mathrm{C}$ en condiciones de oscuridad, a fin de obtener aislamientos para su posterior caracterización cultural de acuerdo con Deschamps \& Wright (1976).

\section{Estudios anatómicos}

El material provino de ejemplares vivos con evidencias de prácticas de poda (heridas con duramen expuesto, $>$ a $10 \mathrm{~cm}$ de diám. aprox.) $\mathrm{y}$ deterioro por actividad fúngica expuesto. Se trabajó con maderas de Populus alba L. (rama de primer orden), Eucalyptus sp. (fuste), Fraxinus pennsylvanica Marshall (rama de primer orden) y Melia azedarach L. (rama de primer orden).

El material fue llevado al laboratorio para su análisis con microscopio estereoscópico (lupa) Nikon SMZ 1000, microscopio óptico (MO) Nikon E200 y microscopio electrónico de barrido (MEB) FEI, modelo Quanta 200 (Servicio de Microscopía Electrónica de Barrido y Microanálisis del LIMF - Facultad de Ingeniería - UNLP). Porciones de madera sin manifestación de deterioro fueron tomadas de los mismos ejemplares y utilizadas como material testigo (datos en Anexo).

Para los estudios con MO, las secciones de madera obtenidas con cuchillas descartables fueron fijadas en formaldehído-ácido acético-alcohol 
(FAA), deshidratadas a través de una serie de etanol y embebidas en Paraplast. Los cortes (10-12 $\mu \mathrm{m}$ de espesor) fueron teñidos con safranina-fast green (D'Ambroggio de Argüeso, 1986). A fin de detectar celulólisis (manifestada como pérdida de birrefringencia), secciones de leño sin tinción fueron analizadas con luz polarizada.

Para las observaciones con MEB, porciones de leño obtenidas con cuchillas descartables fueron montadas sobre las platinas y cubiertas con oro.

La identificación y descripción de los caracteres de diagnóstico de pudrición en el leño fueron realizadas siguiendo a Anagnost (1998) y Schwarze (2007). Para la descripción de la madera testigo se tuvieron en cuenta los caracteres diagnósticos de la IAWA (1989) e Inside Wood Database.

\section{Estudios químicos}

Con el propósito de analizar los cambios químicos causados por L. sulphureus en las maderas, se determinó el contenido de celulosa, lignina insoluble en ácido y de extraíbles en alcohol benceno y agua caliente, de acuerdo con los procedimientos establecidos en las normas TAPPI, descriptos por Rodríguez (1978). Debido a la mayor disponibilidad de material para su procesamiento, en este estudio fueron analizadas sólo las maderas de fresno americano y paraíso gigante (testigos y degradadas). Se realizaron dos repeticiones por tipo de determinación, las cuales se consideraron válidas cuando la diferencia entre ambas fue $\leq$ a $0,1 \%$.

\section{Resultados}

En todos los ejemplares naturalmente infectados se observó, a ojo desnudo, un estado avanzado de pudrición en la zona del duramen. En el caso de $P$. alba se registraron basidiomas asociados a las áreas deterioradas (Fig. 1 A-B). La madera atacada se caracterizó por su coloración castaño-rojiza y por el patrón de ruptura cúbico (presencia de rajaduras paralelas y perpendiculares a la dirección del grano) (Fig. 1 C).

\section{Identificación fúngica}

Los rasgos morfo-biométricos de los basidiomas se correspondieron con lo descripto para $L$. sulphureus (Burdsall \& Banik, 2001; Urcelay et al., 2012). Los aislamientos fueron identificados con los caracteres que conforman la clave patrón de la especie según Wright \& Deschamps (1974); Deschamps \& Wright (1976) y Stalpers (1978). De todos ellos, particularmente facilitaron el diagnóstico la reacción de oxidasas negativa en ácido tánico y gálico, el aspecto del micelio aéreo farináceo/granuloso, el color de la colonia salmón, naranja, la presencia de artrosporas y clamidosporas, los conidióforos con ramificación racimosa a simpodial y conidios (blastoconidios).

\section{Observaciones anatómicas}

Con lupa se registró, por sectores de las muestras, abundante micelio en los vasos como así también en las fracturas (Fig. 1 D-E).

Bajo MO y MEB el tejido apareció deformado (encogido) con respecto al testigo, como producto del ataque fúngico (Figs. $2 \mathrm{~B}-\mathrm{C} ; 3 \mathrm{~B} ; 4 \mathrm{~B} ; 5 \mathrm{D}$ ). Los elementos axiales presentaron un recorrido sinuoso mientras que las fracturas - longitudinales y perpendiculares a la dirección del grano alcanzaron a todos los tipos celulares (elementos de vaso, fibras, células parenquimáticas y traqueidas) (Fig. 2 C, G; Fig. 3 C, F-G; Fig. 4 E, H; Fig. 5 F-G). En algunas muestras se visualizaron conidióforos, conidios - blastoconidios - y clamidosporas (Fig. 2 G; Fig. 3 I).

En todas las maderas la colonización fue mayor en los vasos - aún en aquellos que se encontraban obstruidos por tílides y contenidos gomosos - y en menor proporción en los radios (Fig. 2 B, E-G; Fig. 3 E-G, I; Fig. 4 E-H; Fig. 5 D-E, G). Las tílides aparecieron en ocasiones perforadas por el micelio (Fig. 3 I; Fig. 4 E). Las hifas pasaron de célula a célula atravesando las membranas de las punteaduras, causando la erosión localizada de las mismas principalmente en las fibras y los elementos de vaso (Fig. 2 F-H; Fig. 3 G-H; Fig. 4 I; Fig. 5 $\mathrm{G})$. Se registraron en algunos casos agujeros en las paredes celulares, presumiblemente en asociación con los estadios más avanzados de degradación (Fig. 2 G-H; Fig. 3 G-H; Fig. 4 H-I; Fig. 5 H).

Respecto de la birrefringencia, en términos generales la pérdida fue total en las paredes de las fibras mientras que los vasos aparecieron birrefringentes en mayor o menor grado en todas las muestras (Fig. 2 D; Fig. 3 D; Fig. 4 C-D; Fig. 5 C).

Las particularidades observadas en el leño de cada ejemplar (especie) se detallan en el Cuadro 1. 

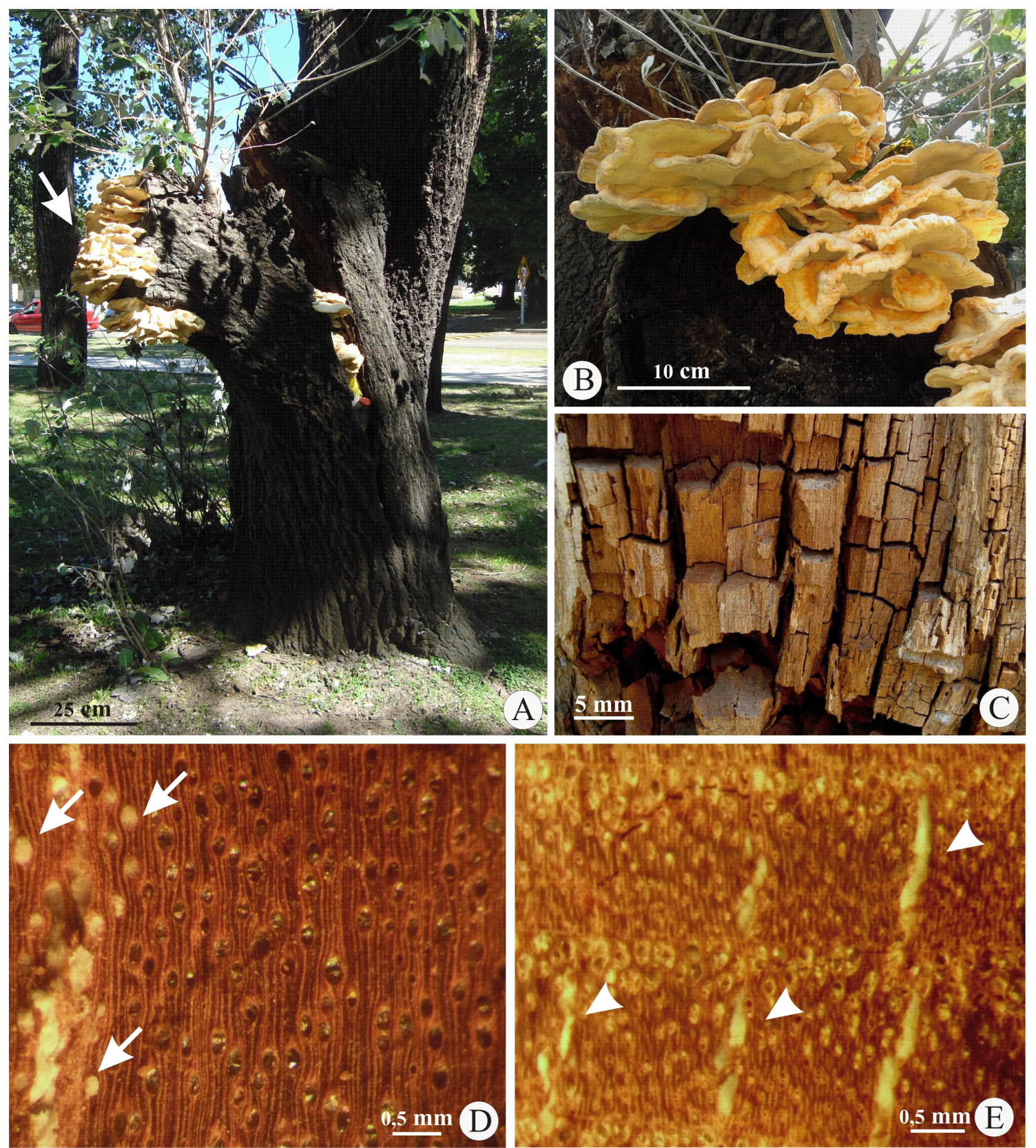

Fig. 1. A-E. Aspecto general de basidiomas de Laetiporus sulphureus y de maderas atacadas por el patógeno. A: ejemplar de álamo blanco donde se observan los basidiomas en una rama de primer orden (flecha). B: detalle de basidiomas. C: aspecto de la madera de eucalipto a ojo desnudo mostrando el patrón de fractura cúbico. D-E: fotomicrografías con lupa. D: vista transversal del leño de eucalipto mostrando la concentración de micelio en los vasos en un sector de la muestra (flechas). E: vista transversal del leño de fresno donde se observa la concentración de micelio en las fracturas (puntas de flecha). 

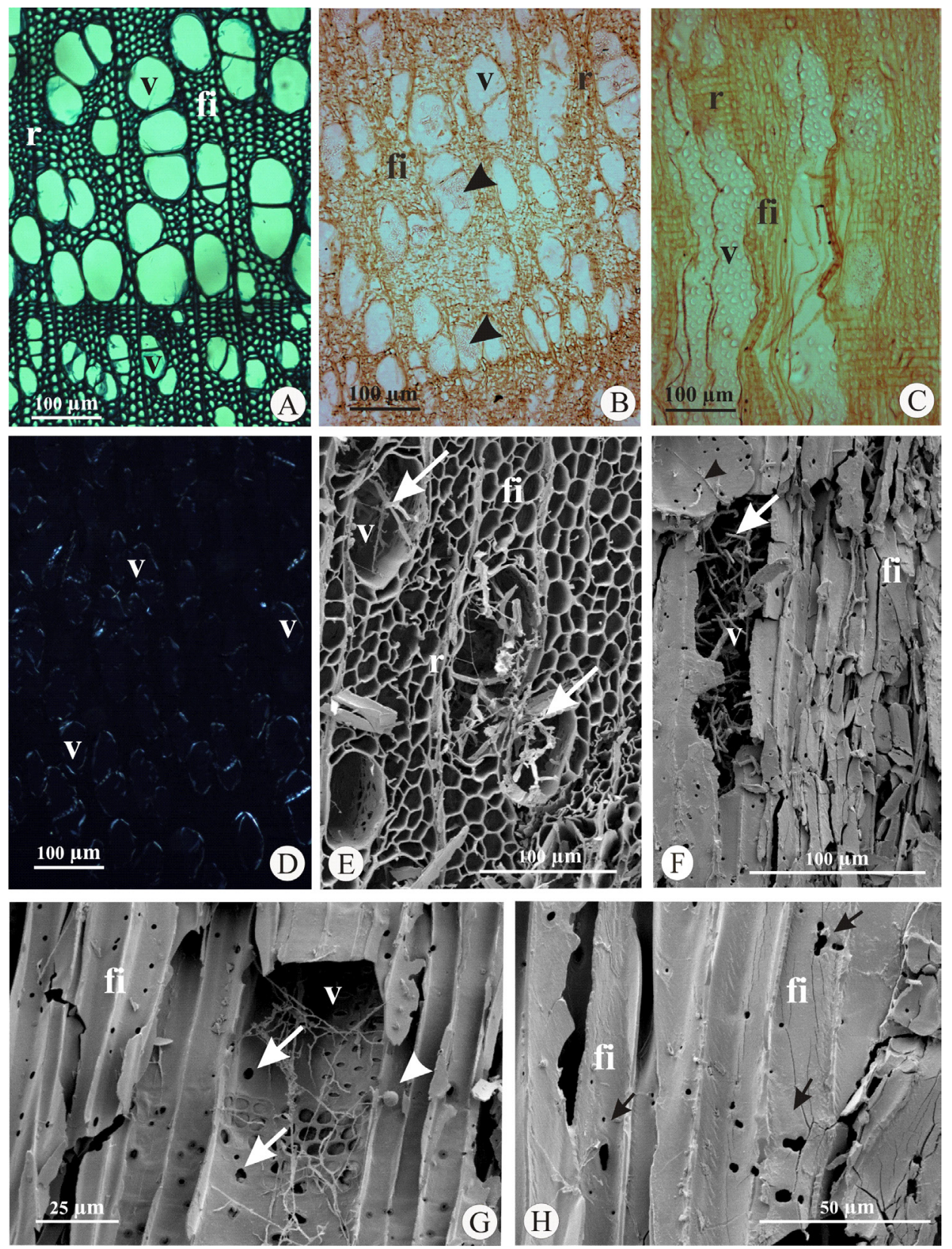

Fig. 2. A-H. Leño de álamo blanco. A-D: fotomicrografías con MO. E-H: fotomicrografías con MEB. A: madera testigo en sección transversal (CT). B-H: madera degradada por L. sulphureus. B: CT donde se observa la deformación y colapso del tejido por sectores. El micelio se concentra en los vasos de mayor tamaño (puntas de flecha). C: sección longitudinal (CL) mostrando el recorrido sinuoso de los vasos y las fibras. D: CT, fotomicrografía con luz polarizada donde se visualiza la birrefringencia de los vasos. E: CT, detalle de concentración de micelio en los vasos (flechas). F-H: CL. F: porción de leño con estadio avanzando de pudrición manifestado por el abundante micelio (flecha) y el colapso de las fibras. Las hifas pasan de célula a célula a través de las punteaduras (punta de flecha). G: erosión pronunciada en la pared de un vaso mostrando los agujeros resultantes de la actividad fúngica (flechas) y la presencia de clamidosporas (punta de flecha). $\mathrm{H}$ : detalle de los agujeros originados en las paredes de las fibras por la coalescencia de punteaduras erosionadas (flechas). Referencias: $\mathrm{fi}=$ fibras; $r=$ radio; $v=$ vaso. 
Bol. Soc. Argent. Bot. 52 (4) 2017
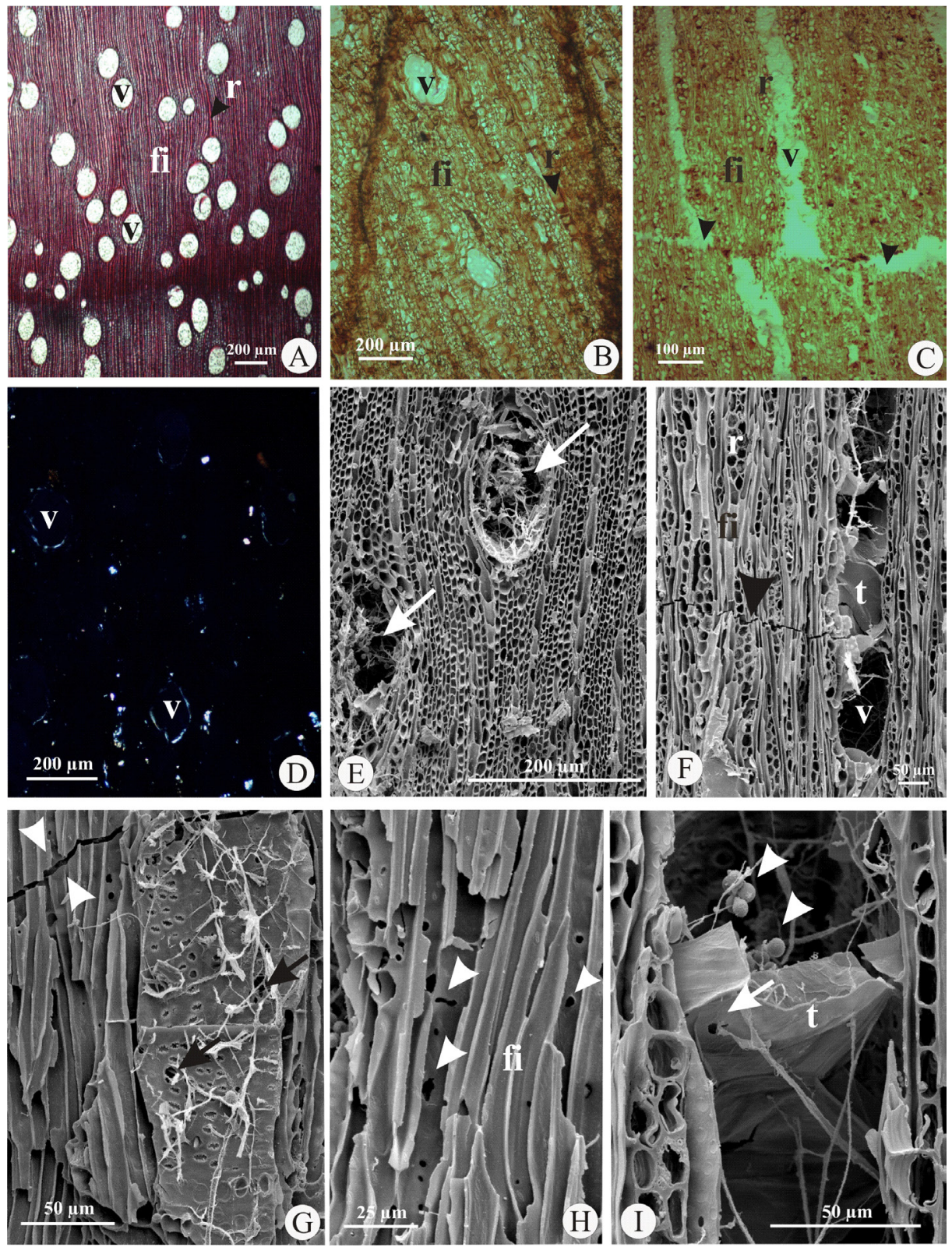

Fig. 3. A-I: Leño de eucalipto. A-D: fotomicrografías con MO. E-I: fotomicrografías con MEB. A: madera testigo en sección transversal (CT). B-I: madera degradada por L. sulphureus. B: CT mostrando la deformación y colapso del tejido por sectores. C: sección longitudinal $(\mathrm{CL})$ donde se observan fracturas perpendiculares al grano (puntas de flecha) e hifas en los vasos. D-F: CT. D: fotomicrografía con luz polarizada donde se visualiza la birrefringencia de los vasos. E: detalle de concentración de micelio en los vasos (flechas). F: detalle de fractura perpendicular al grano (flecha) y abundante micelio en el vaso a la derecha. G-I: estadios presumiblemente más avanzados de degradación en CL. G: presencia de agujeros en la pared de un vaso asociados a la erosión localizada pronunciada (flechas). A la izquierda se visualiza una fractura perpendicular al eje mayor de las fibras (puntas de flecha). $\mathrm{H}$ : detalle de erosión pronunciada en punteaduras de fibras (puntas de flecha). I: detalle de abundante micelio y clamidosporas en el interior de un vaso (puntas de flecha). La tílide aparece perforada por una hifa (flecha). Referencias: $\mathrm{fi}=$ fibras; $r=$ radio; $\mathrm{t}=$ tílide; $v=$ vaso. 

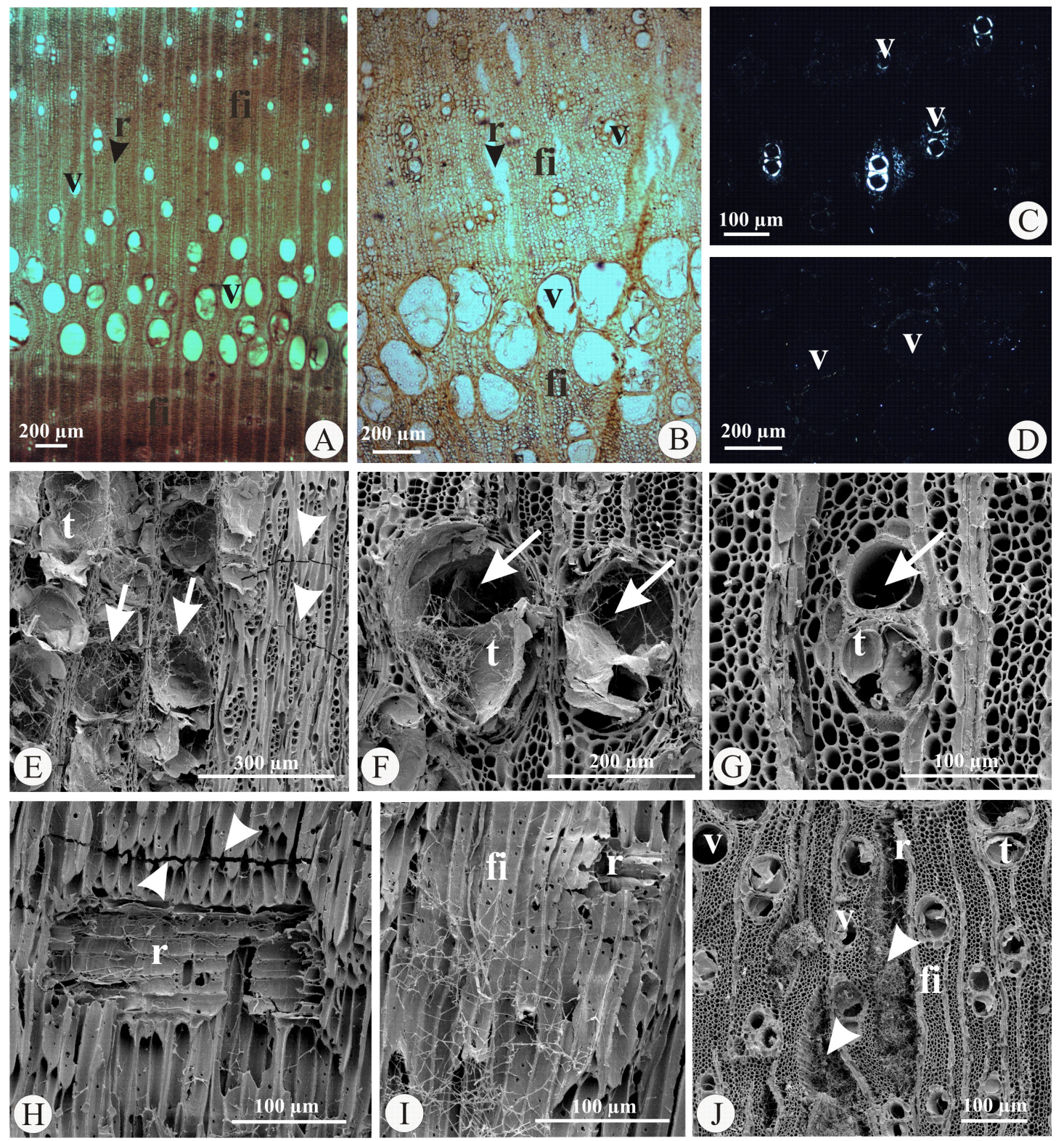

Fig. 4. A-J: Leño de fresno americano. A-D: fotomicrografías con MO. E-J: fotomicrografías con MEB. A: madera testigo en sección transversal (CT). B-J: madera degradada por L. sulphureus. B-D: CT. B: deformación y colapso del tejido por sectores. C-D: fotomicrografías con luz polarizada. C: birrefringencia de vasos y parénquima paratraqueal en el leño tardío. D: tenue birrefringencia de vasos en el leño temprano. $\mathrm{E}$ : corte longitudinal (CL), detalle de fracturas perpendiculares al grano (puntas de flecha) y abundante micelio en los vasos (flechas). F-G: CT. F: abundante micelio en los vasos del leño temprano (flechas). G: micelio prácticamente ausente en los vasos del leño tardío (flecha). H-J: estadios presumiblemente más avanzados de degradación. H-I: CL. H: fractura perpendicular al eje mayor de las fibras (puntas de flecha) y agujeros en las paredes del parénquima de los radios. Nótese que el micelio se distribuye por todo el tejido. I: erosión pronunciada en las punteaduras de las fibras y traqueidas vasicéntricas. J: CT, detalle de espacios originados por la separación celular a la altura de los radios (puntas de flecha). En los espacios se observa abundante micelio. Referencias: $\mathrm{fi}=$ fibras; $\mathrm{r}=$ radio; $\mathrm{t}=\mathrm{t}$ ílide; $\mathrm{v}=$ vaso. 
Bol. Soc. Argent. Bot. 52 (4) 2017
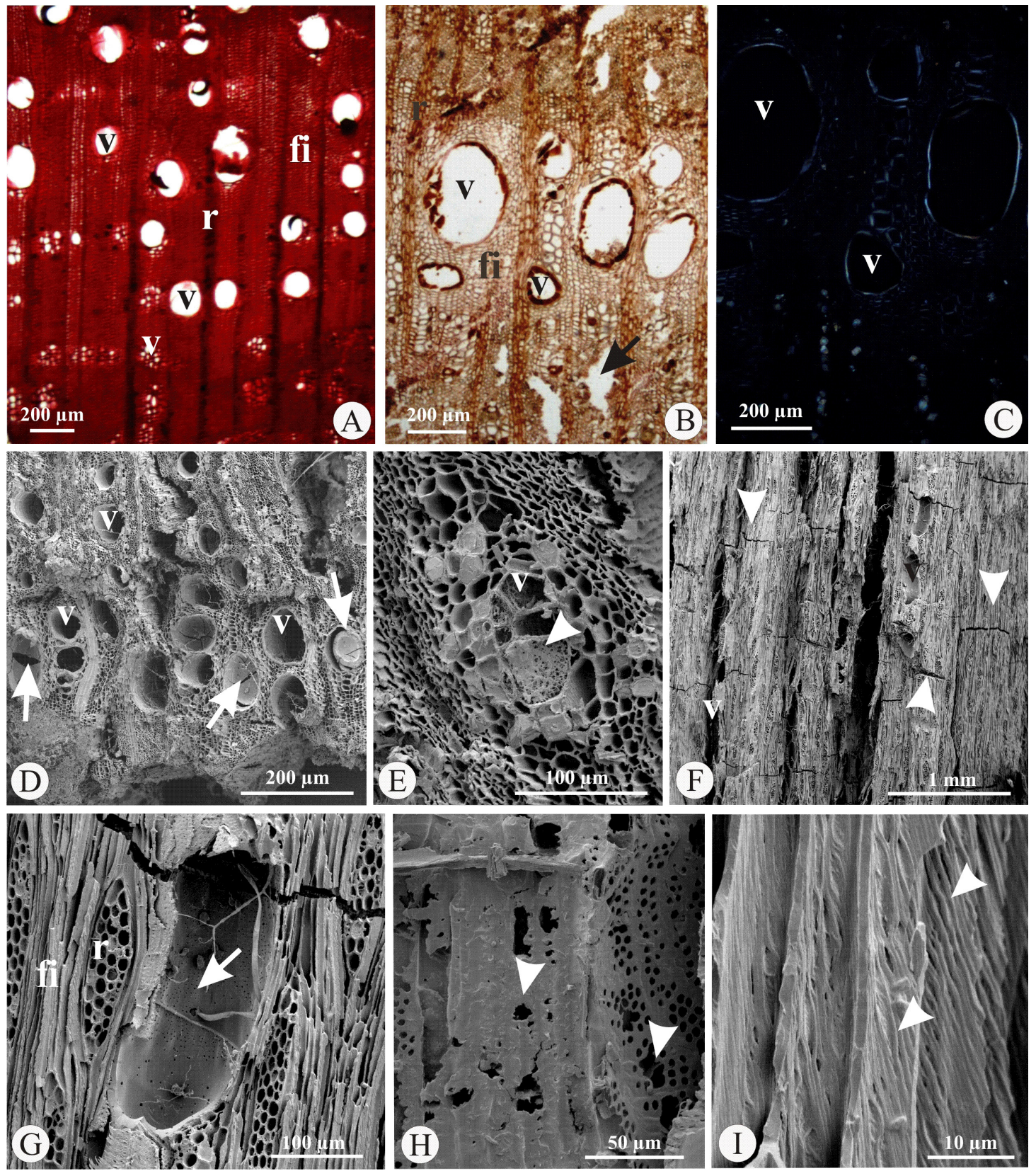

Fig. 5. A-I. Leño de paraíso gigante. A-C: fotomicrografías con MO. D-I: fotomicrografías con MEB. A: madera testigo en sección transversal (CT). B-I: madera degradada por L. sulphureus. B-E: CT. B: deformación y colapso del tejido por sectores. C: fotomicrografías con luz polarizada donde se observa birrefringencia principalmente de vasos y parénquima paratraqueal. D: zona del leño temprano donde los vasos poseen contenidos gomosos (flechas). Nótese el escaso desarrollo de micelio. E: vasos del leño tardío con abundante micelio. F-I: sección longitudinal (CL). F: fracturas perpendiculares al grano (puntas de flecha). G-I: estadios presumiblemente más avanzados de degradación. G: detalle de fractura perpendicular al grano y erosión localizada en la pared de un vaso (flecha). $\mathrm{H}$ : presencia de agujeros en paredes de vaso y parénquima axial como producto de la actividad fúngica (puntas de flecha). I: detalle de rajaduras en espiral en las paredes de las fibras (puntas de flecha). Referencias: $f i=$ fibras; $r=$ radio; $v=$ vaso. 


\section{Estudios químicos}

En la Tabla 1 se presentan los resultados provenientes del análisis químico de muestras de madera de fresno americano y paraíso testigo y con evidencias de pudrición.

Según se observa en la tabla, para ambas muestras y respecto de sus correspondientes testigos, se obtuvo la disminución del porcentaje relativo de celulosa e incrementos en los porcentajes relativos de lignina y extraíbles. En cuanto al paraíso, la disminución en el porcentaje de celulosa y el aumento en los porcentajes de extraíbles fueron menores a los determinados para la madera degradada de fresno.

Tabla 1. Características anatómicas de las maderas testigo y degradadas.

\begin{tabular}{|c|c|c|c|c|}
\hline \multicolumn{5}{|c|}{ RASGOS IDENTIFICADOS } \\
\hline MADERA & TESTIGO & $\begin{array}{l}\text { UBICACIÓN } \\
\text { DEL } \\
\text { MICELIO }\end{array}$ & $\begin{array}{c}\text { ALTERACIONES } \\
\text { MICROESTRUCTURALES }\end{array}$ & BIRREFRINGENCIA \\
\hline $\begin{array}{l}\text { Álamo } \\
\text { blanco }\end{array}$ & $\begin{array}{c}\text { porosidad } \\
\text { semi-anular; } \\
\text { parénquima axial ausente; } \\
\text { fibras paredes } \\
\text { muy delgadas; } \\
\text { radios uniseriados; } \\
\text { ausencia de contenidos } \\
\text { (Fig. 2 A) }\end{array}$ & $\begin{array}{c}\text { vasos } \\
\text { (más abundante } \\
\text { en leño } \\
\text { temprano) } \\
\text { (Fig. } 2 \text { B, E-G) }\end{array}$ & $\begin{array}{c}\text { acentuada } \\
\text { deformación- colapso } \\
\text { del tejido } \\
\text { (Fig. } 2 \text { B-C, F); } \\
\text { erosión y coalescencia } \\
\text { de punteaduras en } \\
\text { fibras y vasos } \\
\text { (Fig. } 2 \text { G-H) }\end{array}$ & $\begin{array}{l}\text { vasos } \\
\text { (Fig. } 2 \text { D) }\end{array}$ \\
\hline Eucalipto & $\begin{array}{c}\text { porosidad difusa; } \\
\text { tílides en vasos; } \\
\text { parénquima vasicéntrico; } \\
\text { fibras paredes } \\
\text { delgadas a espesas; } \\
\text { radios bi-seriados con } \\
\text { contenidos } \\
\text { (Fig. 3 A) }\end{array}$ & $\begin{array}{c}\text { vasos } \\
\text { (Fig. } 3 \mathrm{E}-\mathrm{G}, \mathrm{I})\end{array}$ & $\begin{array}{l}\text { deformación - colapso } \\
\text { de la totalidad del tejido } \\
\text { (Fig. } 3 \text { B-C, F-G); } \\
\text { erosión y coalescencia } \\
\text { de punteaduras en } \\
\text { fibras y vasos } \\
\text { (Fig. } 3 \text { G-H) }\end{array}$ & $\begin{array}{c}\text { muy tenue, sólo } \\
\text { en algunos vasos } \\
\text { (Fig. } 3 \text { D) }\end{array}$ \\
\hline $\begin{array}{c}\text { Fresno } \\
\text { americano }\end{array}$ & $\begin{array}{l}\text { porosidad circular; } \\
\text { tílides en vasos; } \\
\text { parénquima y traqueidas } \\
\text { vasicéntricos; } \\
\text { parénquima paratraqueal } \\
\text { en bandas; } \\
\text { fibras paredes } \\
\text { delgadas a espesas; } \\
\text { radios multi-seriados } \\
\text { (Fig. } 4 \mathrm{~A} \text { ) }\end{array}$ & $\begin{array}{c}\text { vasos } \\
\text { (predominante en } \\
\text { leño temprano) } \\
\text { (Fig. } 4 \text { E-G) }\end{array}$ & $\begin{array}{l}\text { deformación - colapso } \\
\text { más pronunciados } \\
\text { en leño temprano } \\
\text { (Fig. } 4 \mathrm{~B}, \mathrm{H}, \mathrm{J}) ; \\
\text { erosión-coalescencia } \\
\text { punteaduras } \\
\text { principalmente en fibras } \\
\text { (Fig. } 4 \mathrm{I}) ; \\
\text { separación celular a la } \\
\text { altura de los radios } \\
\text { (Fig. } 4 \text { B-J) }\end{array}$ & $\begin{array}{l}\text { leño temprano } \\
\text { muy tenue en vasos } \\
\text { (Fig. } 4 \mathrm{D}) ; \\
\text { leño tardío } \\
\text { pronunciada en } \\
\text { vasos, en ocasiones } \\
\text { en parénquima } \\
\text { vasicéntrico } \\
\text { (Fig. } 4 \mathrm{C})\end{array}$ \\
\hline Paraíso & $\begin{array}{c}\text { porosidad circular; } \\
\text { contenidos gomosos en } \\
\text { vasos, principalmente } \\
\text { en leño temprano; } \\
\text { parénquima axial } \\
\text { paratraqueal con cristales; } \\
\text { fibras paredes } \\
\text { delgadas a espesas; } \\
\text { radios multi-seriados } \\
\text { (Fig. } 5 \mathrm{~A})\end{array}$ & $\begin{array}{l}\text { predominante } \\
\text { en vasos } \\
\text { leño tardío, } \\
\text { sin contenidos } \\
\text { gomosos } \\
\text { (Fig. } 5 \text { D-E) }\end{array}$ & $\begin{array}{c}\text { deformación - colapso } \\
\text { leño tardío y transición leño } \\
\text { temprano-tardío afectando } \\
\text { todos los tipos celulares } \\
\text { (Fig. } 5 \text { B, F-G); } \\
\text { agujeros en paredes de } \\
\text { vasos y parénquima } \\
\text { (Fig. } 5 \text { G-H); } \\
\text { rajaduras en espiral en fibras } \\
\text { (Fig. } 5 \text { I) }\end{array}$ & $\begin{array}{c}\text { leño tardío } \\
\text { sólo en algunos vasos; } \\
\text { leño temprano } \\
\text { vasos y parénquima } \\
\text { axial } \\
\text { y en radios por } \\
\text { sectores } \\
\text { (Fig. } 5 \mathrm{C} \text { ) }\end{array}$ \\
\hline
\end{tabular}


Tabla 2. Composición en términos de celulosa, lignina y extraíbles de la madera testigo y degradada de fresno americano y paraíso.

\begin{tabular}{|c|c|c|c|c|c|}
\hline \multirow{2}{*}{\multicolumn{2}{|c|}{ Muestra }} & \multirow{2}{*}{$\begin{array}{c}\text { Celulosa } \\
\text { (\%) }\end{array}$} & \multirow{2}{*}{$\begin{array}{l}\text { Lignina } \\
\text { (\%) }\end{array}$} & \multicolumn{2}{|c|}{$\begin{array}{c}\text { Extraíbles } \\
(\%)\end{array}$} \\
\hline & & & & ROH-B & $A C$ \\
\hline \multirow{2}{*}{ Fresno americano } & Testigo & 60.3 & 24.98 & 5,85 & 10,58 \\
\hline & Madera degradada & 6.51 & 44.52 & 18.28 & 20.76 \\
\hline \multirow{2}{*}{ Paraíso } & Testigo & 47.65 & 29.63 & 2.21 & 6.74 \\
\hline & Madera degradada & 13.06 & 56.64 & 10.33 & 7.7 \\
\hline
\end{tabular}

Referencias: $\mathrm{ROH}-\mathrm{B}$ : alcohol benceno; $\mathrm{AC}$ : agua caliente

\section{Discusión y Conclusiones}

En las especies del arbolado de la ciudad de La Plata abordadas en este estudio fue identificado el hongo xilófago $L$. sulphureus causando pudrición castaña en duramen. Los resultados obtenidos se correspondieron con lo citado por diversos autores sobre el daño producido por este patógeno en especies de latifoliadas y gimnospermas de otras regiones del mundo, así como en ámbitos urbanos de nuestro país (Rayner \& Boddy, 1988; Sede \& López, 1999; Schwarze, 2004; Urcelay et al., 2012). La localización de los basidiomas, del deterioro, como también las heridas observadas (en particular las que evidencian prácticas de poda) son compatibles con el tipo de pudrición y la estrategia de colonización conocida para la especie. Laetiporus sulphureus es considerado principalmente como patógeno responsable de pudriciones de copa - ramas como lugar de origen de la pudrición y evolución descendente - , con estrategia de colonización "heart rot" (pudrición del duramen), en la cual el establecimiento se inicia con la llegada de esporas a heridas con duramen expuesto (Rayner \& Boddy, 1988).

Los caracteres macroscópicos observados en las maderas analizadas - color castaño, patrón de fractura cúbico, presencia de micelio - así como su fragilidad, son considerados indicadores de estadios avanzados de pudrición castaña (Wilcox, 1968; Anagnost, 1998; Schwarze, 2007). En este tipo de deterioro la despolimerización de los carbohidratos provoca la deshidratación del tejido $\mathrm{y}$, como consecuencia, su encogimiento y ruptura siguiendo un patrón cúbico característico. La madera degradada queda constituida por un frágil marco de lignina que se desintegra bajo presión. Por su parte, la oxidación parcial de la lignina otorga la coloración castaña (parda) que caracteriza y da el nombre a la pudrición (Zabel \& Morrell, 1992; Blanchette, 1995).

A nivel microscópico, la visualización de agregaciones de conidios, clamidosporas y abundante micelio en los leños analizados también es indicador de pudrición avanzada, y coincide con lo observado por Schwarze et al. (2000b) en el duramen de Robinia pseudoacacia naturalmente infectado por L. sulphureus. Según Blanchette (1995), durante los primeros estadios del proceso de degradación por cepas de pudrición castaña, las hifas son escasas y dispersas dentro de los lúmenes celulares, tornándose más abundantes a medida que la degradación avanza.

La estrategia y el patrón de colonización del hongo estarían relacionados con su capacidad enzimática y con la estructura de la madera (Zabel \& Morrell, 1992). En el presente estudio se evidenció una mayor concentración de micelio en los vasos y radios en todas las maderas, con un predominio en los vasos de mayor diámetro del leño temprano en álamo y fresno, causando la fuerte demarcación de esta zona del anillo a ojo desnudo y con lupa. Este patrón de colonización coincide con lo observado por Schwarze et al. (2000b) en madera de $R$. pseudoacacia degradada por L. sulphureus. Las características del leño - tipos celulares, distribución, diámetro de los vasos, contenidos celulares, grado de lignificación - condicionan la presencia miceliar (Boddy \& Rayner, 1983; Schwarze \& Fink, 1998; Schwarze, 
2007). En términos generales, en las latifoliadas la colonización del leño se produce a través del sistema axial (vasos particularmente) y de las células parenquimáticas radiales (sistema radial). En especies de porosidad circular, los vasos del leño temprano (de mayor diámetro) constituyen una ruta rápida para la colonización axial; en oposición, en el leño tardío, el mayor espesor de la pared de las fibras afecta negativamente la dispersión radial del hongo (Schwarze et al., 1997; 2000b).

La presencia de extraíbles en los lúmenes celulares - situación frecuente en el duramen y observada en algunas de las muestras analizadas conforman barreras a la colonización, si bien existen antecedentes en torno a la capacidad de ciertos hongos de superarlas mediante su destrucción o con estrategias alternativas de degradación (Shigo \& Marx, 1977; Boddy \& Rayner, 1983; Schwarze \& Fink, 1997; 1998). En paraíso, los vasos del leño temprano mostraron una mayor obstrucción con contenidos gomosos, motivo por el cual se registró la concentración del micelio en el leño tardío. Laetiporus sulphureus es reconocido por su capacidad de degradar los extractivos de la madera (Rayner \& Boddy, 1988; Schwarze et al., 2000b). La perforación de los contenidos gomosos y de las tílides - en este último caso en la madera de fresno - por parte del micelio, constituyen evidencias de ello. No obstante, es sabido que dichos extraíbles (su naturaleza, cantidad y distribución), condicionan la colonización y la degradación fúngica (Schwarze et al., 1997; Schwarze, 2007).

Caracteres como la destrucción completa de la pared celular originando agujeros y la presencia de senderos de erosión (en álamo), podrían asociarse a la coalescencia de punteaduras erosionadas, rasgos típicos de estadios avanzados de degradación (Wilcox, 1968, 1993a, b; Anagnost, 1998).

La deformación y el colapso del tejido resultantes de la actividad fúngica, se corresponden con las particularidades anatómicas de cada leño. En este sentido, la mayor deformación y colapso observados en la madera de álamo podrían asociarse a la ausencia de contenidos celulares, al poco espesor de las paredes de las fibras citados para la especie (muy delgadas, InsideWood Database) y a los estrechos radios parenquimáticos. Por su parte, la menor deformación y colapso registrados en los leños de fresno, eucalipto y paraíso se corresponden con la presencia de contenidos en los vasos y en el parénquima axial y radial — tílides, compuestos gomosos, cristales - , con el mayor espesamiento de las paredes de sus fibras (delgadas a espesas, InsideWood, Database) y con el mayor ancho de sus radios parenquimáticos. Los contenidos celulares y el grado de lignificación dificultan la deformación celular (Rivera \& Lenton, 1999).

La separación celular es otra característica observada en ocasiones en maderas con pudrición castaña causada por distintas cepas xilófagas (Wilcox, 1968; Murace et al., 2006). En el presente trabajo, la misma fue identificada sólo en la madera de fresno a la altura de los radios parenquimáticos - entre sus células constituyentes - como también en la intersección radios/fibras circundantes, posiblemente como producto de la acción mecánica del micelio en esa zona del tejido. Schwarze et al. (2000b) también observaron colapso mecánico a nivel radios parenquimáticos en madera de $R$. pseudoacacia naturalmente infectada por $L$. sulphureus. No obstante, coincidimos con Wilcox (1993a) en cuanto a que esta característica no puede ser considerada como rasgo de diagnóstico ya que no se manifiesta con regularidad.

En relación a la birrefringencia, la pérdida de esta propiedad fue prácticamente total en las maderas analizadas, en asociación con estadios avanzados de pudrición castaña. Autores como Wilcox (1968; 1993a; b) y Anagnost (1998) consideran la pérdida de esta característica como la evidencia más relevante de diagnóstico de las pudriciones castañas. Existen antecedentes sobre el comportamiento diferencial de la degradación dentro del anillo anual así como entre distintos tipos celulares, debidos a diferencias en el grado de lignificación de las paredes y en la disposición de las microfibrillas de celulosa. En el leño tardío la mayor lignificación de las células conforma una barrera física que limita/retarda la difusión de los hongos de pudrición castaña, dada su actividad mediante un sistema difusible que concentra su acción sobre los carbohidratos del estrato $\mathrm{S}_{2}$ de la pared (Rayner \& Boddy 1988; Schwarze et al., 2003; Schwarze, 2007). Respecto de las microfibrillas, su disposición radial en el estrato $\mathrm{S}_{2}$ de la pared de las fibras contribuye con la difusión de los agentes de degradación, rasgo ausente en el parénquima y en los elementos de vaso (Schwarze et al., 2000a; b; 2003). Esto permite explicar la pérdida de birrefringencia en las fibras de la totalidad de los leños, en ambos sectores del 
anillo, y su persistencia en los vasos. Respecto del parénquima - tanto axial como radial — la pérdida de birrefringencia fue prácticamente total en todas las muestras analizadas. Si bien Schwarze et al. (2000b) detectaron birrefringencia en el parénquima de maderas de Robinia y Quercus infectadas por $L$. sulphureus, lo hallado resultaría del avanzado estado de degradación como también del rol del parénquima durante la colonización fúngica (Boddy \& Rayner, 1983). La pérdida de birrefringencia (celulólisis) causada por estos hongos, principalmente en las paredes de las fibras, constituye una herramienta útil al momento de significar y predecir los riesgos de pérdida de estabilidad de los ejemplares dañados.

En referencia a los estudios químicos, lo obtenido se corresponde con lo esperado para este tipo de pudrición respecto de la degradación selectiva de los carbohidratos. Los hongos responsables de pudrición castaña como L. sulphureus degradan holocelulosa; la lignina sólo es parcialmente oxidada (Blanchette, 1995; Schwarze, 2007). La intensa despolimerización de la celulosa y de las hemicelulosas determina en la madera degradada aumentos relativos en los porcentajes de lignina y extraíbles, estos últimos también influenciados por los carbohidratos fúngicos (Kirk \& Highley, 1973; Pandey \& Pitman, 2003; Karppanen et al., 2008). Los hongos causantes de pudrición castaña despolimerizan selectivamente la holocelulosa rápidamente desde los estadios iniciales del proceso a velocidad mayor a la que los productos resultantes de su degradación pueden ser metabolizados (Zabel \& Morrell, 1992; Schmidt, 2006).

En el caso de la madera de paraíso, la disminución en el porcentaje relativo de celulosa y el consecuente aumento en el porcentaje de ambos tipos de extraíbles, en todos los casos menores a los de fresno, también podría ser explicado a partir de los rasgos anatómicos de su leño. Según se mencionó, los contenidos de la madera - como gomas y cristales - condicionan la colonización y la degradación fúngica (Schwarze et al., 1997; Schwarze, 2007). Kirk \& Highley (1973) mencionan la influencia del sustrato por sobre las cepas xilófagas, en las tasas de remoción de los principales componentes estructurales de la pared celular.

En las pudriciones castañas la rápida e incipiente destrucción de los carbohidratos determina la disminución drástica de las propiedades de resistencia de la madera, lo cual atenta contra la estabilidad de los ejemplares, poniendo en riesgo a la población, sus bienes y servicios en el contexto urbano.

Laetiporus sulphureus es un patógeno frecuente del arbolado urbano, reconocido por disminuir notablemente la capacidad resistente de las maderas naturalmente infectadas (Schwarze \& Fink, 1994; Schwarze, 1995, tomados de Schwarze et al., 2000b). Debe tenerse en cuenta que, ante situaciones de pudrición total del duramen, si bien el riesgo de quiebre y vuelco es elevado, depende de numerosos factores. En un árbol vigoroso el cambium y la albura intacta garantizan que un árbol crezca en diámetro y de este modo es compensada la destrucción causada por un hongo xilófago (Boddy \& Rayner, 1983; Sterken, 2005).

\section{Agradecimientos}

Los autores agradecemos a la Universidad Nacional de La Plata por el financiamiento de esta investigación (Proyecto A/296).

\section{Bibliografía}

ANAGNOST, S. E. 1998. Light microscopic diagnosis of wood decay. IAWA J. 19: 141-167.

BLANCHETTE, R. A. 1995. Degradation of the lignocellulose complex in wood. Can. J. Bot. 73(Suppl. 1): 999-1010.

BODDY, L. \& A. D. M. RAYNER. 1983. Origins of decay in living deciduous trees: the role of moisture content and a re-appraisal of the expanded concept of tree decay. New Phytol. 94: 623-641.

BURDSALL, H. H. JR. \& A. M. T. BANIK. 2001. The genus Laetiporus in North America. Harvard Pap. Bot. 6: 43-55.

D’AMBrogiO DE ARGÜESO, A. 1986. Manual de técnicas histológicas en plantas. Ed. Hemisferio Sur, Buenos Aires.

DELUCCHI, G., A. A. JULIANELLO \& R. F. CORREA. 1993. Los espacios verdes y el arbolado urbano en el área de La Plata. I - Orígenes y evolución hasta el presente. Rev. Fac. Cs. Nat. y Museo.

DESCHAMPS, J. R \& J. R. WRIGHT. 1976. Clave para el reconocimiento en cultivo de las especies xilófagas de Basidiomycetes argentinae. Rev. Invest. Agrop., INTA, Bs. As., Rep. Argentina. Serie 5, Pat. Veg. Vol. 12, No2. 
DIRECCIÓNDEESPACIOSVERDES, MUNICIPALIDAD DE LA PLATA. 1983. Arboles de la ciudad de La Plata. 1 ra ed. Municipalidad de La Plata.

GAMAUF, C., B. METZ \& B. SEIBOTH. 2007. Degradation of plant cell wall polymers by fungi. In: Kubicek, C. P., I Druzhinina (eds), The Mycota IV, Environmental and Microbial Relationships, pp. 325-340. Springer-Verlag Berlin Heidelberg.

GREEN III, F. \& T. L. HIGHLEY. 1997. Mechanism of brown-rot decay: paradigm or paradox. Int. Biodeterior. Biodegradation 39: 113-124.

IAWA COMMITTEE. 1989. IAWA list of microscopic features for hardwood identification. IAWA Bull. 10: 219-332.

INSIDE WOOD DATABASE. Disponible en: http:// insidewood.lib.ncsu.edu/search. [Acceso: Octubre del 2016].

KARPPANEN, O., M. VENALAINEN, A. HARJU \& T. LAAKSO. 2008. The effect of brown-rot decay on water adsorption and chemical composition of scots pine heartwood. Ann. For. Sci. 65(610): 1-8.

KIRK, T. K. \& T. L. HIGHLEY. 1973. Quantitative changes in structural components of conifer woods during decay by white and brown rot fungi. Phytophatology 63: 1338-1342.

MURACE, M., M. L. LUNA, G.D. KEIL \& N. DE CRISTÓFANO. 2006. Anatomical changes in Willow Wood Decayed by the brown rot fungus Coriolellus malicola (Basidiomycota). Bol. Soc. Argent. Bot. 41: 159-166.

OTA, Y., T. HATTORI, M. T. BANIK, G. HAGEDORN, K. SOTOME, S. TOKUDA, \& Y. ABE. 2009. The genus Laetiporus (Basidiomycota, Polyporales) in East Asia. Mycol. Res. 113: 1283-1300.

PANDEY, K. K. \& A. J. PITMAN. 2003. FTIR studies of the changes in wood chemistry following decay by brownrot and white-rot fungi. Int. Biodeterior. Biodegradation 52: 151-160.

RAYNER, A. D. M. \& L. BODDY. 1988. Colonization of the standing tree in Fungal decomposition of wood. Wiley, Chichester, England.

RILEY, R., A. A. SALAMOV, D. W. BROWN, L. G. NAGY, D. FLOUDAS, B. W. HELD, A. LEVASSEUR, V. LOMBARD, E. MORIN, R. OTILLAR, E. A. LINDQUIST, H. SUN, K. M. LABUTTI, J. SCHMUTZ, D. JABBOUR, H. LUO, S. E. BAKER, A. G. PISABARRO, J. D. WALTON, R. A. BLANCHETTE, B. HENRISSAT, F. MARTIN, D. CULLEN, D. S. HIBBETT \& I.V. GRIGORIEV. 2014. Extensive sampling of basidiomycete genomes demonstrates inadequacy of the white-rot/brown-rot paradigm for wood decay fungi. PNAS 111: 9923-9928.

RIVERA, S. M. \& M. S. LENTON. 1999. La xilología y las propiedades mecánicas de cinco maderas nativas argentinas. Quebracho 7: 72-78.
ROBLEDO, G. \& C. URCELAY. 2009. Hongos de la madera en árboles nativos del centro de Argentina. 1ra ed. Universidad Nacional de Córdoba, Córdoba, Argentina.

RODRÍGUEZ, L. 1978. Métodos de análisis empleados en la industria papelera. 1ra. ed. Centro de Investigaciones en Celulosa y Papel. Universidad Industrial de Santander, Colombia.

SCHMIDT, O. 2006. Wood and tree decay. Biology, damage, protection and use. $1 \mathrm{st}$ ed. Springer-Verlag Berlin Heidelberg, Germany.

SCHWARZE, F.W.M.R. 2004. Forest Pathology: Heart Rot and Wood Decay. In: Burley, J., J. Evans, J. Youngquist (eds), Encylopedia of Forest Sciences, pp. 808-816. Elsevier Science.

SCHWARZE, F.W.M.R. 2007. Review wood decay under the microscope. Fungal Biol. Rev. 21: 133-170.

SCHWARZE, F. W. M. R., S. BAUM \& S. FINK. 2000a. Resistance of fiber regions in wood of Acer pseudoplatanus degraded by Armillaria mellea. Mycol. Res. 104: 1126-1132.

SCHWARZE, F. W. M. R., J. ENGELS \& C. MATTHECK. 2000 b. Fungal strategies of wood decay in trees. 1st ed. Springer Verlag, Berlin.

SCHWARZE, F. W. M. R. \& S. FINK. 1997. Reaction zone penetration and prolonged persistence of xilem rays in London plane wood degraded by the basidiomycete Inonotus hispidus. Mycol. Res. 101: 1207-1214.

SCHWARZE, F.W.M.R. \& S. FINK. 1998. Host and cell type affect the mode of degradation by Meripilus giganteus. New Phytol. 139: 721-731.

SCHWARZE, F. W. M. R., S. FINK \& D. DEFLORIO. 2003. Resistance of parenchyma cells in wood to degradation by brown rot fungi. Mycol. Prog. 2: 267-274.

SCHWARZE, F. W. M. R., D. LONSDALE \& S. FINK. 1997. An overview of wood degradation patterns and their implications for tree hazard assessment. Arb. Jour. 21: 1-32.

SEDE, S. \& S. LOPEZ.1999. Xylophagous fungi of urban trees in Buenos Aires City. Mycologist 13: 173-175.

SHIGO,A.L.\&H.G.MARX. 1977. Compartmentalization of decay in trees. USDA For. Serv., Agric. Inf. Bull. 405.

STALPERS, J. A. 1978. Identification of wood-inhabiting Aphyllophorales in pure culture. Stud. Mycol. 16: 1-248.

STERKEN, P. 2005. A Guide For Tree-Stability Analysis. Royal Belgian Library.

TERHO, M. \& A. M. HALLAKSELA. 2005. Potential hazard characteristics of Tilia, Betula, and Acer trees removed in the Helsinki City Area during 2001-2003. Urban For. Urban Greening 3: 113-120. 
Bol. Soc. Argent. Bot. 52 (4) 2017

URCELAY, C., G. ROBLEDO, F. HEREDIA, G. MORERA \& F. GARCÍA MONTAÑO. 2012. Hongos de la madera en el arbolado urbano de Córdoba. 1ra ed. Instituto Multidisciplinario de Biología Vegetal (UNC-CONICET).

WILCOX, W. W. 1968. Changes in wood microstructure through progressive stages of decay. USDA For. Serv. Res. Paper FPL 70: 1-41.

WILCOX, W. W. 1993 (a). Comparative morphology of early stages of brown-rot wood decay. IAWA J. 14: 127-138.

WILCOX, W. W. 1993 (b). Comparison of scanning electron microscopy and light microscopy for the diagnosis of early stages of brown rot decay. IAWA J. 14: 219-226.
WRIGHT, J. E. \& J. R. DESCHAMPS. 1974. Basidiomicetos xilófilos de la región Mesopotámica. II. Rev. Invest. Agrop., Serie 5, Pat. Veg. 12: 128-204. ZABEL, R. A. \& J. J. MORRELL. 1992. Wood microbiology. Decay and its prevention. 1st ed. Academic Press Inc.

Recibido el 16 de amrzo de 2017, aceptado el 8 de junio de 2017. 
M. Murace et al. - Pudrición castaña en latifoliadas por L. sulphureus

\section{Anexo: Material estudiado}

Eucalyptus sp. ARGENTINA. Prov. Buenos Aires: Pdo. La Plata, calle 26, entre calles 70 y 71, 10-III2016, Murace et al. 205 (LPAG).

Fraxinus pennsylvanica. ARGENTINA. Prov. Buenos Aires: Pdo. La Plata, calle 65, entre calles 24 y 26, 8-XI-2015, Murace et al. 204 (LPAG).

Melia azedarach. ARGENTINA. Prov. Buenos Aires: Pdo. La Plata, calle 72, entre calles 25 y 26, 20-X2015, Murace et al. 208 (LPAG).

Populus alba. ARGENTINA. Prov. Buenos Aires: Pdo. La Plata, Av. 32, entre calles 3 y 4, 8-IV-2016, Murace y Luna 423 (LPAG). 
